\title{
Rotational vertebral artery syndrome treated via an anterior approach and selective decompression only
}

\author{
Jung Hoon Kang, Soo Bin Im, Je Hoon Jeong, Dong-Seong Shin \\ Depertment of Neurosurgery, Soonchunhyang University Bucheon Hospital, Soonchunhyang University College of \\ Medicine, Bucheon, Republic of Korea
}

We present the case of a 38-year-old male who complained of repeated dizziness and syncope. Rotational vertebral artery syndrome (RVAS) was diagnosed via videonystagmoraphy (VNG), computed tomography angiography (CTA) and three-position digital subtraction angiography (DSA). In the neutral position, CTA and DSA revealed left vertebral artery (VA) stenosis at the C2 transverse foramen and right VA hypoplasia. When the head was turned to the right, the blood flow stopped at the C2 level. The bony structure around the VA at the C2 transverse foramen was decompressed via an anterior surgical approach, and the symptoms resolved. This case present the precise stenotic point evaluation by three-position DSA is crucial for the planning of surgical treatment.

Keywords Anterior decompression, Nystagmus, Posterior circulation infarction, Rotational vertebral artery syndrome, Videonystagmography
J Cerebrovasc Endovasc Neurosurg.

2019 September;21(3):158-162

Received : 7 December 2018

Revised : 5 May 2019

Accepted : 2 September 2019

Correspondence to Soo Bin Im Depertment of Neurosurgery, Soonchunhyang University Bucheon Hospital, Soonchunhyang University College of Medicine, Bucheon, Republic of Korea

Tel : 82-32-621-5290

Fax : 82-32-621-5016

E-mail : isbrzw@gmail.com

ORCID : http://orcid.org/0000-0002-1442-0482

This is an Open Access article distributed under the terms of the Creative Commons Attribution NonCommercial License /http://creativecommons.org/licenses/by-nc/3.0) which permits unrestricted noncommercial use, distribution, and reproduction in any medium, provided the original work is properly cited.

\section{INTRODUCTION}

Dizziness triggered by rotating the head is a characteristic symptom of rotational vertebral artery syndrome (RVAS). However, dizziness has many causes, and patients who complain of dizziness provoked by rotating the head should also be evaluated in terms of a peripheral disorder, such as benign paroxysmal positional vertigo (BPPV). Videonystagmography (VNG) is useful for distinguishing between peripheral disorder and central disorder $(1,2)$. There are various treatment options, ranging from conservative treatment such as rehabilitation to surgery (3). Decompression without fusion is the recommended first-line therapy and a posterior approach is generally preferred to decompress the VA at the C1-2 level (4-6). We present a case of RVAS diagnosed via
VNG, CTA and three-position DSA. The exact stenotic point was determine based on three-position DSA. The patient was treated via anterior VA decompression at the $\mathrm{C} 2$ transverse foramen, not posterior approach. A satisfactory outcome was achieved.

\section{CASE DESCRIPTION}

A 38-year-old male suffering from alcoholism visited our outpatient department complaining of repeated dizziness and a buzzing sound in the left ear. His first ear symptom was a hearing difficulty commencing 1 year prior. Dizziness and a buzzing sound developed when he turned his head to the right, commencing a few months prior. Sometimes, the dizziness was so severe that he could not open his eyes. Then, he failed to maintain balance and fell, losing 


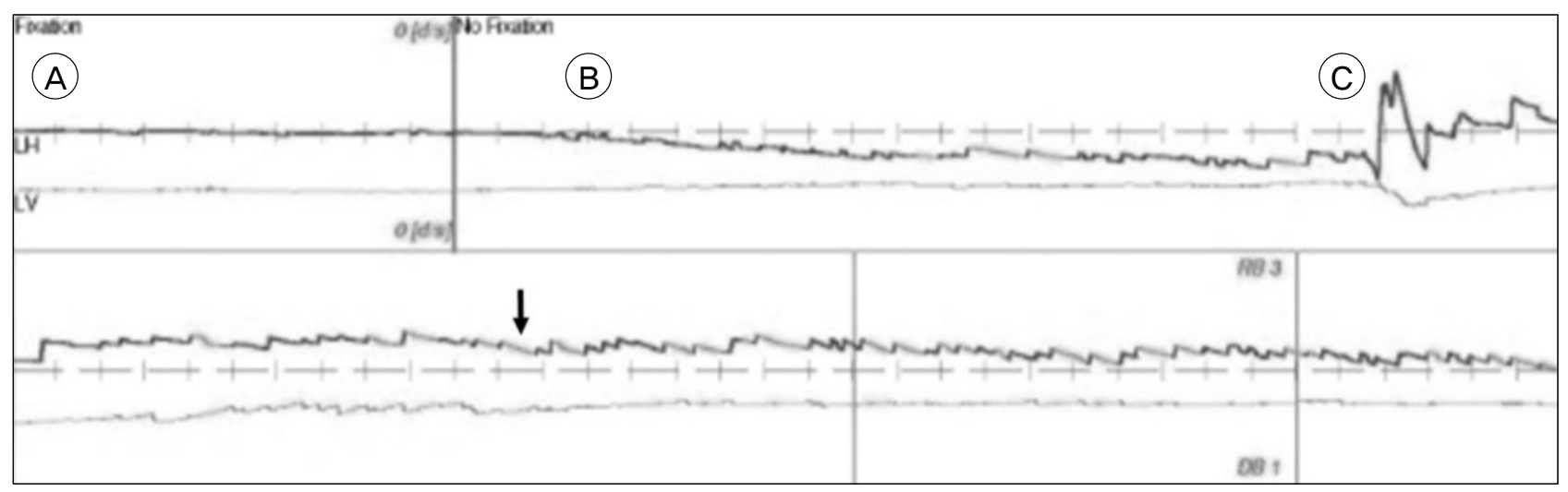

Fig. 1. Videonystagmography revealed no nystagmus in the neutral position (A) or when the head was turned to the left (B). Right-beating nystagmus (black arrow) with a down-beat component was observed when the head was turned to the right (C).

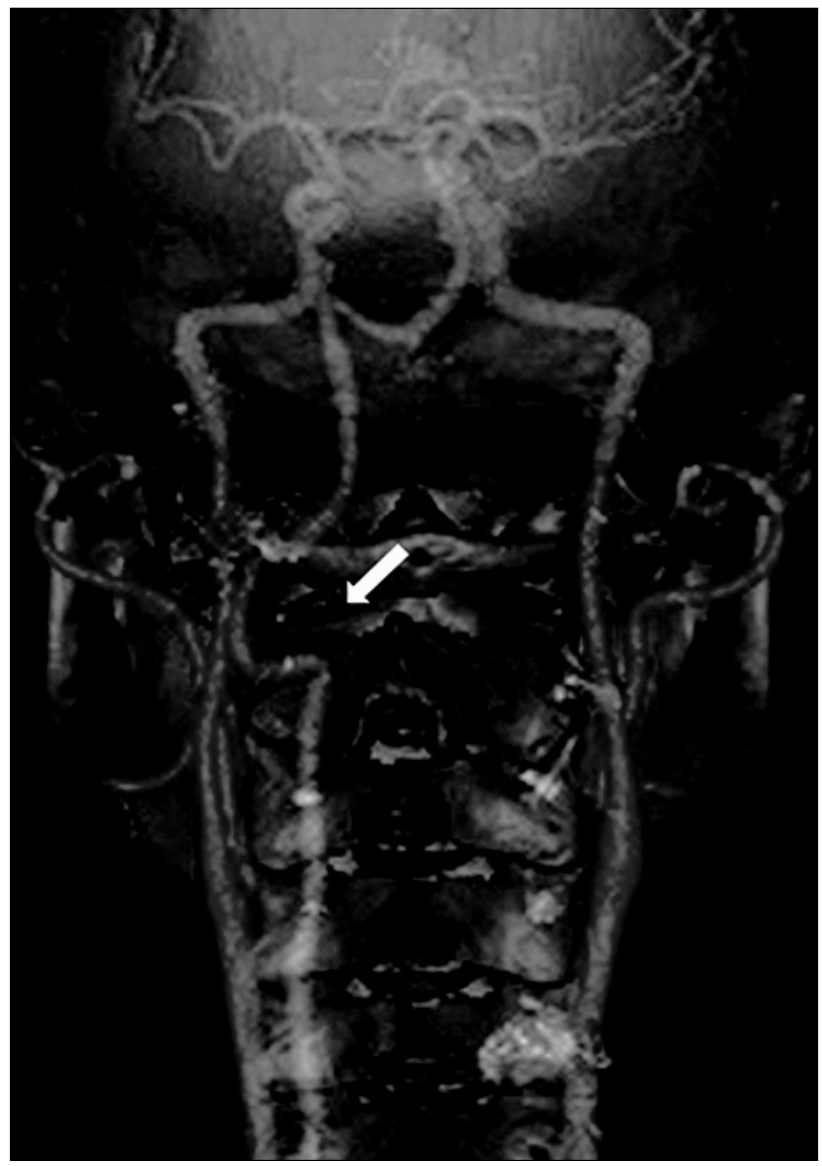

Fig. 2. The posteroanterior view of three-dimensional-reconstruction computed tomography angiography revealed left vertebral artery stenosis at the C2 transverse foramen (white arrow).

consciousness for 3-4 seconds. On examination, we found that the symptoms appeared only when he turned the head to the right, whether he was stand- ing, sitting, or lying. No symptoms were evident when the head was rotated to the left or in the neutral position. A down-beat nystagmus appeared when the head turned to the right.

We used VNG to determine whether the problem was peripheral or central. VNG revealed right- beating nystagmus with a down-beat component when the head was turned to the right (Fig. 1), indicating a central rather than a peripheral origin. We scheduled brain and neck CTA, brain MRI, and three-position DSA to evaluate central origin. CTA revealed a hypoplastic right VA and left VA stenosis at the lateral curvature of the VA at $\mathrm{C} 2$ transverse foramen. (Fig. 2) Brain MRI revealed a tiny, acute ischemic infarction in the right cerebellum. (Fig. 3) DSA was performed in three positions (with the head neutral, $90^{\circ}$ to the left, and $90^{\circ}$ to the right). In the neutral position, left VA stenosis was observed at the C2 transverse foramen, as on CTA. Notably, when the head was turned to the left, the VA stenotic lesion became wider than in the neutral position. When the head was turned to the right, the blood flow tapered at the C3-4 level and was totally occluded at the C2 level. (Fig. 4) Few minutes after angiography with $90^{\circ}$ to the right, the patient lost consciousness and DSA was halt. As the right VA was hypoplastic and flow almost absent, the posterior circulation was highly dependent on the left VA. We concluded that the left VA became kinked at the $\mathrm{C} 2$ transverse foramen when the head was turned 


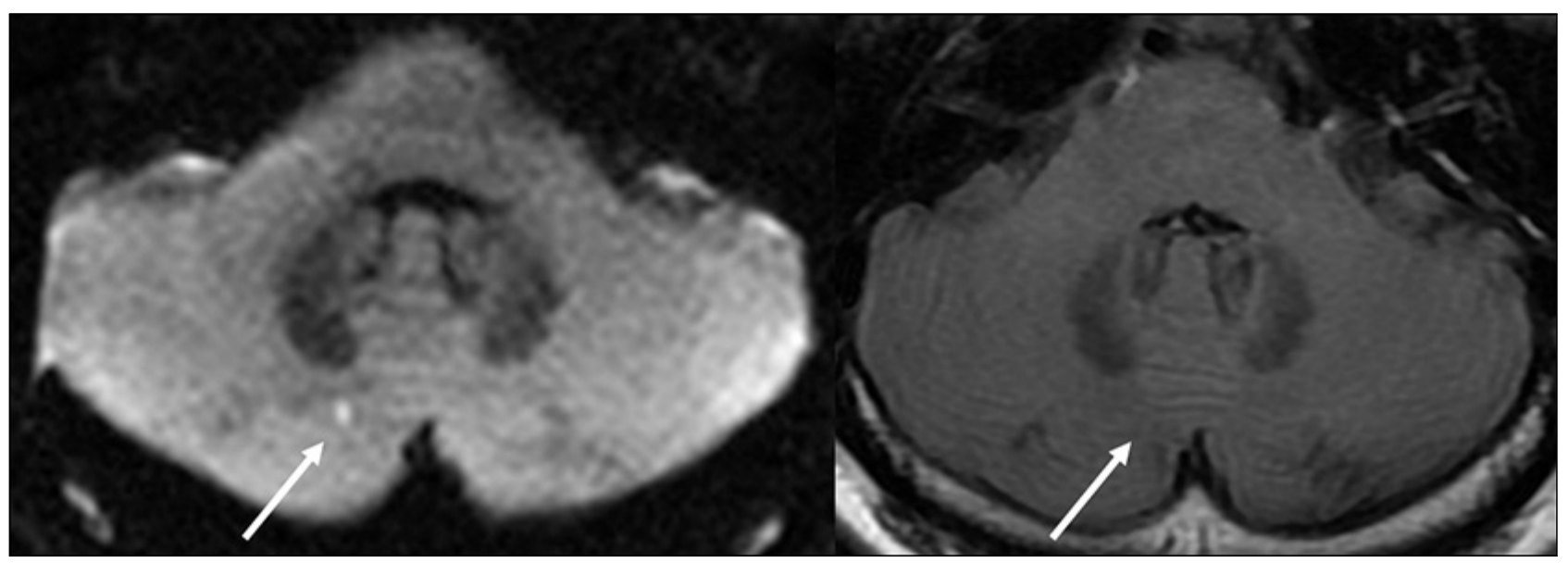

Fig. 3. Diffusion and T2 FLAIR magnetic resonance imaging shows a tiny acute ischemic infarction in the right cerebellum (right arrow).

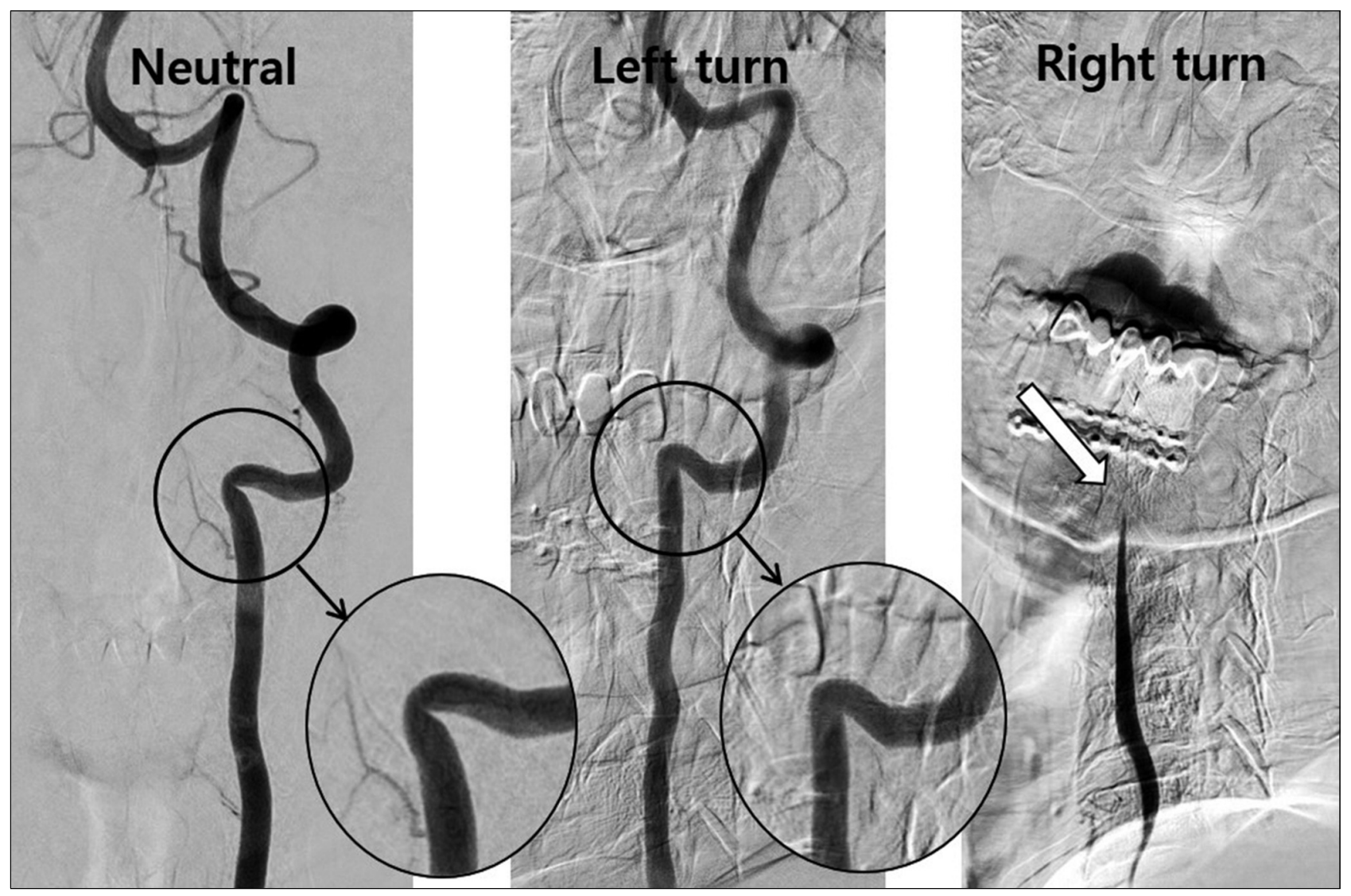

Fig. 4. Neutral. The anteroposterior view of left vertebral artery (VA) angiography with the head in the neutral position revealed left VA stenosis at the C2 transverse foramen. Left turn. The lateral view of left VA angiography when the head was turned to the left revealed that the stenotic VA at C2 became wider than in the neutral position. Right turn. The lateral view of left VA angiography when the head was turned to the right showed that blood flow decreased at the C3-4 level (black arrow) and stopped at the C2 level (white arrow).

to the right. We decided to perform anterior decompression of the left VA.
The patient was placed in the supine position and a transverse skin incision was created on the medial 

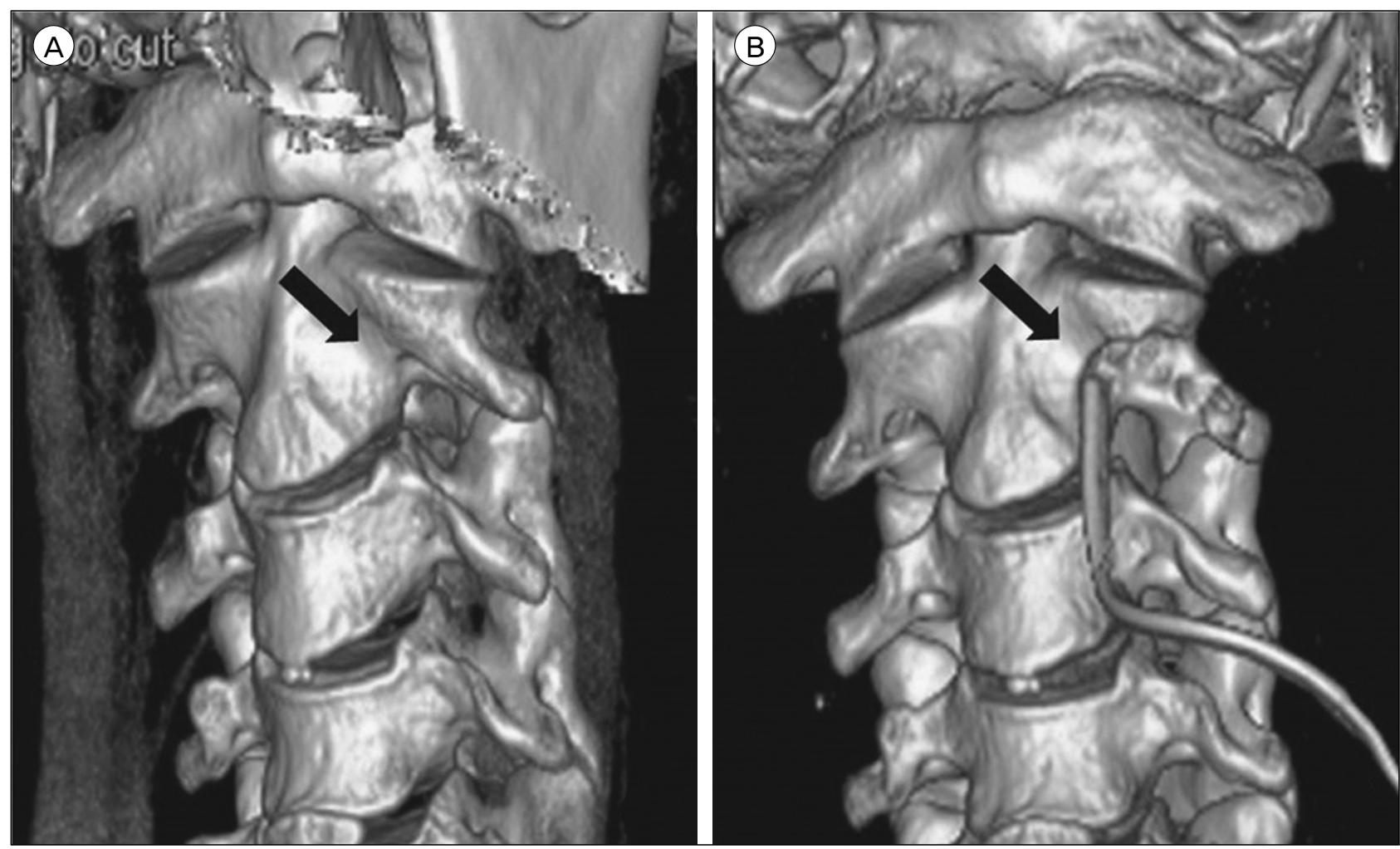

Fig. 5. A) Preoperative computed tomography (CT) three-dimensional (3D)-reconstruction image. B) The postoperative CT 3D-reconstruction image showed that the anterior portion of the transverse foramen had been removed; the foramen was thus widened while preserving the articular facet (black arrow).

border of the sternocleidomastoid muscle at the C2-3 level. The anterolateral portion of the left transverse foramen that covered the VA was carefully drilled. The VA was fully decompressed, and VA pulsation immediately became more active. Postoperative CTA showed a wider transverse foramen than preoperatively (Fig. 5). The symptoms improved dramatically after surgery. Neck movement was not limited, and no instability was noticed on a dynamic X-ray of cervical spine.

\section{DISCUSSION}

It is challenging to distinguish between nystagmus of peripheral and central origin; this requires consideration of various clinical symptoms and features. The direction of nystagmus after a positioning maneuver can point to a central disorder. Paroxysmal down-beat, up-beat, or pure torsional nystagmus is considered to reflect a central origin $(2,7)$. Our patient's nystagmus contained a down-beat component, and thus was not exclusively right-beating, suggesting a central origin. We were able to determine the need for CTA and DSA at risk of radiation exposure and invasive using VNG, a non-invasive and radiation free test.

Rotatory VA stenosis at the C1-C2 level with reduced blood flow can be observed in normal individuals, reflecting relative immobilization of the VA at the $\mathrm{C} 2$ and $\mathrm{C} 1$ transverse foramina. During head rotation, the atlantoaxial joint is fixed, whereas the $\mathrm{C} 1$ contralateral transverse foramen moves forward and downward, kinking the contralateral VA at the transverse foramen and stretching the extraspinal VA segment, decreasing blood flow $(8,9)$. This does not normally trigger infarction of the posterior circulation because the remaining contralateral VA and the anastomosis confer adequate circulation (10). If the opposite VA is hypoplastic or rendered stenotic or occlusive by arteriosclerotic changes, the posterior circulation is 
vulnerable to infarction in most RVAS cases (3). In the case reported here, as the right VA was hypoplastic and flow almost absent, the posterior circulation was highly dependent on the left VA. We concluded that when the head was turned right the left VA became kinked at the C2 transverse foramen.

The anatomical course of the VA was the most important factor when choosing an approach $(4,5)$. The VA moves anteriorly from C6 to C3 after passing the lateral curvature at $\mathrm{C} 2$, and then ascends sharply posteriorly. The VA at C1-2 is best visualized via a posterior approach and below C3 via an anterior approach. Although a posterior approach is generally preferred to decompress the VA at the C1-2 level, some reports described successful decompression via an anterior approach $(11,12)$. In our case, the stenotic lesion lay at the $\mathrm{C} 2$ transverse foramen not in the C1-2 joints therefore it is best visualized via anterior approach. It is important to choose the surgical approach that best visualized exact stenotic point, rather than simply determined by the stenotic level.

\section{CONCLUSION}

A patient with repeated dizziness and syncope was diagnosed with RVAS. Down beating nystagmus on VNG indicated origin of dizziness was central. The three-position DSA showed the stenotic point of VA became narrowed and widened according to the head rotation. The precise stenotic point evaluation by three-position DSA is crucial for the planning of surgical treatment.

\section{REFERENCES}

1. Mekki S. The role of videonystagmography (VNG) in assessment of dizzy patient. The Egyptian Journal of
Otolaryngology. 2014;30(2):69. doi: 10.4103/1012-5574.133167.

2. Choi KD, Choi JH, Kim JS, Kim HJ, Kim MJ, Lee TH, et al. Rotational vertebral artery occlusion: mechanisms and long-term outcome. Stroke. 2013;44(7):1817-24. doi: 10.1161/STROKEAHA.113.001219. PubMed PMID: 23696552.

3. Duan G, Xu J, Shi J, Cao Y. Advances in the Pathogenesis, Diagnosis and Treatment of Bow Hunter's Syndrome: A Comprehensive Review of the Literature. Interv Neurol. 2016;5(1-2):29-38. doi: 10.1159/000444306. PubMed PMID: 27610119; PubMed Central PMCID: PMCPMC4934473.

4. Lu DC, Zador Z, Mummaneni PV, Lawton MT. Rotational vertebral artery occlusion-series of 9 cases. Neurosurgery. 2010;67(4):1066-72; discussion 72. doi: 10.1227/NEU.0b013e3181ee36db. PubMed PMID: 20881570.

5. Zaidi HA, Albuquerque FC, Chowdhry SA, Zabramski JM, Ducruet AF, Spetzler RF. Diagnosis and management of bow hunter's syndrome: 15-year experience at barrow neurological institute. World Neurosurg. 2014;82(5):733-8. doi: 10.1016/j.wneu.2014.02.027. PubMed PMID: 24549025.

6. Matsuyama T, Morimoto T, Sakaki T. Comparison of C1-2 posterior fusion and decompression of the vertebral artery in the treatment of bow hunter's stroke. J Neurosurg. 1997;86(4):619-23. doi: 10.3171/jns.1997.86.4.0619. PubMed PMID: 9120624.

7. U. Büttner CHTB. Diagnostic Criteria for Central versus Peripheral Positioning Nystagmus and Vertigo: a Review. Acta Oto-Laryngologica. 2009;119(1):1-5. doi: 10.1080/ 00016489950181855

8. Wakayama K, Murakami M, Suzuki M, Ono S, Shimizu $\mathrm{N}$. Ischemic symptoms induced by occlusion of the unilateral vertebral artery with head rotation together with contralateral vertebral artery dissection--case report. J Neurol Sci. 2005;236(1-2):87-90. doi: 10.1016/j.jns.2005.04.010. PubMed PMID: 15979646.

9. Jost GF, Dailey AT. Bow hunter's syndrome revisited: 2 new cases and literature review of 124 cases. Neurosurg Focus. 2015;38(4):E7. doi: 10.3171/2015.1.FOCUS14791. PubMed PMID: 25828501.

10. TOOLE JF, TUCKER SH. Influence of head position upon cerebral circulation: studies on blood flow in cadavers. AMA Archives of Neurology. 1960;2(6):616-23.

11. Seki T, Hida K, Akino M, Iwasaki Y. Anterior decompression of the atlantoaxial vertebral artery to treat bow hunter's stroke: technical case report. Neurosurgery. 2001;49(6):1474-6. Epub 2002/02/28. PubMed PMID: 11859829.

12. Cevik S, Katar S, Hanımoğlu H. C1-C2 transverse foramen decompression by anterolateral approach as an alternative treatment in Bow Hunter's Syndrome. Asian journal of neurosurgery. 2018;13(2):411. 